\title{
Promoting Multilingual Communicative Competence for the Labor Market
}

\author{
Sadik Madani Alaoui \\ Sidi Mohammed Ben Abdellah University \\ Faculty of Letters \& Human Sciences, Dhar El Mehraz, Fès Morocco
}

doi: 10.19044/esj.2017.v13n7p201 URL:http://dx.doi.org/10.19044/esj.2017.v13n7p201

\begin{abstract}
Over the past decades, globalization has been completely changing the context of the labor market such that the importance of learning languages as a means of cultural understanding cannot be ignored. As a result, employers look for people who have experience from different countries and have shown that they are able to adapt to different languages and cultures. The issue of learning languages and developing intercultural competence stands at the heart of human experience, reflecting not only cultures but also providing a key to better understanding them. The paper supports the promotion of a dialogue among various partners, educators and decision-makers as a good way to respond to the challenges associated with the development of language skills for the job market. Seen from an employment perspective, promoting multilingual communicative competence for the labor market is currently regarded as a means to an end. This paper examines ways to sharpen the focus on employability promotion in the Moroccan ENSAM School of Engineering. Moroccan would-be engineers will be shown to increase their chances of finding jobs, not only nationally but also internationally through greater multilingual competence.
\end{abstract}

Keyterms: Intercultural Competence, Employability, Multilingual Competence, Labor Market

\section{Introduction}

Throughout the past decades, Morocco's vision for the future has become a justifiable and an all-inclusive economy, which includes enhancing the quality of education and training throughout the lives of its citizens. This important prerequisite to achieve multilingual communicative competence for labor market is one way to envision the future of labor market through unravelling the power that exists in our future learners. A host of language skills are needed and regular surveys of the need for communication in the 
labour market have been carried out nationally and brought to the attention of education planners and career advisers. The need to be able to work in international scenarios demands both challenges and interest in both communication and language skills in tune with the labor market requirements of the $21^{\text {st }}$ century. Preparing new syllabi for Engineering graduates means increasing chances for employability and strengthening communication skills and competence among students so they can cope with the corporate culture and overcome those challenges. The global market expects competent graduates able to interact with people of different countries around the world to develop job related-skills that are widely recognized in the world of business under the guise that in the world of today, achievement comes to those who have skills appropriate to various situations, careers and positions.

\section{Purpose and rationale}

The central premise of this article is to promote multilingual communicative competence for the labor market. Specifically, ways to sharpen the focus of employability chances among Moroccan engineers at the Higher National School of “Arts et Métiers" (ENSAM) will be examined. A descriptive analysis with regard to language skills and communication activities in the textbook will be offered to help give an idea about the efficiency of the program content with respect to the development of multilingual communicative competence. The guiding rationale is grounded in a large body of literature which gives credence and credibility to the strong association between textbook analysis and development of multilingual communicative competence. The following questions are posited to orient the resulting research.

- $\quad$ Do the prescribed textbook units and topics at all levels motivate learners?

- $\quad$ Do they encourage communicative approaches?

- $\quad$ Do they help in the development of communicative competence?

\section{Background and global perspective}

Education has been a practice and tested route to enhance people's prospects, giving access to better employment and raised standards of living. Contemporary approaches to higher education support underline the urgent need for "users" to reward the price of instruction, as education officials gradually view it as something that benefits the individual, rather than as a "public good" where profits accrue to society. The demand for foreign languages and communication skills is steadily rising on the world labour market. In order to reduce the gap between offer and demand of language skills and to increase the motivation of learners, experts in education 
encourage the development and dissemination of new methods of teaching languages. These methods should be basically learner-centered, and practically oriented and more applied to professional contexts. This implies that effective communication and cultural awareness are important elements of language teaching, as intercultural competence, ability to work in multilingual and multicultural teams, flexibility and good communication skills are highly demanded by the employers. Since these skills can be acquired or enhanced through spending a study exchange or work placement abroad, mobility of both learners and teachers needs to be further increased and supported.

Although much is known about the linguistic map of different countries in the world, the total number of languages spoken all over the world is vast and undefined, of which some are used for communication purposes either as second, third or later-acquired languages. In Morocco, existing data (Ennaji 2005; Melouk 2001) show that there are countless more bilingual or multilingual persons than there are monolingual. Besides, schooled people have more opportunities to be educated through a second or a later-acquired language using French and later English. The presence of official mother tongues embodied in Amazigh (Berber), Arabic as well as foreign languages that have a great influence on Moroccan educational system such as French, English, Spanish and currently German and Italian, have made of Morocco a multilingual country par excellence. The primary force behind the present situation is the mobility and employability of its citizens.

The success of Multilingualism has been acknowledged to highlight languages as a way for small and medium-sized companies to broaden their access to markets. In Morocco, multilingualism is a common perspective offered to every educated citizen rather than an infrequent exception. In this respect, Ennaji (2005 1) describing the Moroccan cultural context, states that

[t]he relationship between multiculturalism and multilingualism is a strong one. The process of readjustment to a second or a third culture entails the use of new knowledge, rules of communication, and inferential strategies. It is generally coupled with the learning of new languages, in which case multiculturalism implies multilingualism.

Given that, languages and cultures in Morocco have always been in conflict with regard to their appropriateness for use in education and government, and while, in the past, mother tongues have not been deemed important in elementary, secondary or higher education institutions, the use of French and English, today, along with Arabic, is particularly increasing in higher education, a fact potentially for graduate students to find positions in the of job market at a global level. 
While the Moroccan linguistic situation is a complex-mosaic, the idea of mastery of foreign languages in addition to Arabic and Amazigh is a must. It is widely acknowledged that the Moroccan multilingual education system has succeeded in creating a learning context whereby the coexistence of various languages has empowered Moroccan students to face future challenges insofar as communication is concerned. A host of civilizations have deeply influenced the country and contributed to its linguistic and cultural diversity to generate what is commonly known today as a multilingual profile. The eminent Moroccan lexicographer, Lakhdar Ghazal, ex-director of the Institute of Studies and Research on Arabization (ISRA) in Rabat, claims that, if Arabization is a duty, multilingual education is a necessity insomuch as it serves the enrichment of Standard Arabic.

Furthermore, Moroccan multilingual policy seems to be closely linked to the merging challenges of globalization and to the increasing importance of Science and Technology in this new millennium. In this light, Moroccan educationalists have not only devised a number of approaches that highlight employability skills within the education curriculum but have also shed light on syllabus designers to work together to define these skills. Employability skills, a set of abilities incorporating professional knowledge and expertise necessary for success in the workplace, are usually regarded as required qualifications for any job positions in a professional context. The outcome of those efforts has emphasized the role played by elementary and secondary schools as well as universities in fostering these employability related-skills among Moroccan learners. To expand opportunities for employment in national companies, teaching material has been identified as an important way designed to enhance understanding of the content and to facilitate learning in general.

It has been further acknowledged that textbook supplements are designed to enhance understanding of the content and facilitate learning in general. As such, learners should make great progress in learning languages and cultures via the teaching materials in textbooks. By means of their content, texts, and language learning activities, learners develop competencies to bring them success in the world of business. Learners needs, wants, and interests provide a plausible incentive for positive leaning to take place and to make them communicate specific content in English with ease and comfort.

\section{Multilingual competence}

According to Hymes (1966), communicative competence is a construct used in language studies, which denotes the individual's use of not only the grammatical knowledge related to syntax, morphology, phonology 
but also the social knowledge about how and when to use utterances appropriately. Communicative competence has been defined as:

... [t]he ability to function in a truly communicative setting that is a dynamic exchange in which linguistic competence must adapt itself to the total information input, both linguistic and paralinguistic of one or more interlocutors. Communicative competence includes grammatical competence (sentence level grammar),socio-linguistic competence (an understanding of the social context in which language is used), discourse competence (an understanding of how utterances are strung together to form a meaningful whole), and strategic competence (a language user's employment of strategies to make the best use of what s/he knows about how a language works, in order to interpret, express, and negotiate meaning in a given context (Savignon1985130).

As to multilingual communicative competence, researchers have not yet agreed upon a single definition of it (Saville-Mroike 2006).There is nothing new in claiming that multilingual communication is a complex construct that is inconstant, elastic, and subject to manipulation; still its multi-faceted nature, along with its mutation across disciplinary boundaries and theoretical paradigms, makes it hard to define precisely. Scholars have recognized that multilingual competence as conspicuously differentiated from that of monolinguals. Based on this view, researchers have started to compare multilingual speakers with monolinguals to define their distinctive abilities. In contrast with previous definitions of "multilingual competences as the sum of discrete monolingual competences" (Kemp2009), it is

the capacity to communicate linguistically and to interact culturally held by an actor who masters to varying degrees many languages and who also masters to varying degrees the experience of many cultures, all the while being able to manage this entire language and cultural capital (Coste et al. 1997 12).

Within this modern perspective, Morocco has launched a major initiative to improve English language teaching in its education system, of which the main goals is to improve the communicative competence of its graduates in the area of second language acquisition, communication, and communicative competence through communicative language teaching. This initiative has implications for a wide range of actors, ranging from the educational institutions and institutions of vocational training to employers, businesses, and decision makers in the national Ministries.

\section{The ENSAM educational profile}

The Ecole Nationale Supérieure d'Arts et Métiers (ENSAM) is a prestigious Engineering school. It is a public scientific, cultural, and professional institution, under the authority of the Ministry of Higher 
Education and Research located in the Moroccan imperial city of Meknes. Founded in 1997 to fill the late kingdom with engineers in this versatile state, four branches of Engineering are taught, which are (1) Mechanical Engineering and Structures, (2) Industrial Engineering and Production, (3) Electromechanical Engineering, (4)Engineering of Materials and Manufacturing Processes of Engineering. In addition, the ENSAM also offers basic training and vocational and Master's degree in Logistics, Transport and Maintenance.

The following table represents the structure of the five training years after high school.

\begin{tabular}{|c|c|c|}
\hline \multirow{2}{*}{$\begin{array}{c}\text { Stream } \\
\text { Math, Physics, and } \\
\text { Technology }\end{array}$} & Scientific Baccalaureate & \multirow{2}{*}{$\begin{array}{c}\text { Diplomas } \\
\text { DUT, DEUG, } \\
\text { SPE, BTS or } \\
\text { equivalent. }\end{array}$} \\
\hline & $\begin{array}{l}1^{\text {st }} \text { Year integrated Preparatory Cycle } \\
2^{\text {nd }} \text { Year integrated Preparatory Cycle }\end{array}$ & \\
\hline \multirow{3}{*}{$\begin{array}{c}\text { Four Training Tracks:1. } \\
\text { Mechanical engineering } \\
\text { and Structure, } 2 . \\
\text { Industrial Engineering } \\
\text { and Production } \\
\text { Manufacturing, } 3 . \\
\text { Electromechanical } \\
\text { engineering. } \\
\text { 4. Engineering of } \\
\text { materials }\end{array}$} & $3^{\text {rd }}$ Year Engineering Cycle & \multirow{3}{*}{ BA or equivalent } \\
\hline & $4^{\text {th }}$ Year Engineering Cycle & \\
\hline & $5^{\text {th }}$ Year Engineering Cycle & \\
\hline Professional Life & $\begin{array}{c}\text { Engineering Diploma of “Arts et } \\
\text { Métiers” }\end{array}$ & Doctoral Program \\
\hline
\end{tabular}

Table 1 -Training System at the ENSAM School of Engineering

The ENSAM School of Engineering has a total of 1020 students who often contribute in design projects all throughout their graduate curriculum. The language of instruction is French and English in an Engineering ESP component which results in the normalization of many aspects of the various modules to contribute to the students training in the course of the three final years of engineering degree.

\section{Methodology}

The research methodology for this study begins within the application of a descriptive analysis (Robinson, 1991) of the textbook. The research design focuses on the analysis of three textbooks, which were prescribed by the ENSAM school of Engineering, whose purpose is to determine whether they fulfill their communicative teaching objectives as well as help enhance communicative competence of students' engineers, able to use their expertise in science and Math to do their jobs. Examination of 
the effective implementation of the textbook to see if it meets the diverse communicative learning needs of future engineers will be revealed and analyzed. Based on the attitudes expressed by the teachers, advantages of using the textbook will be mentioned.

The Participants: The participants involved in this study are six English instructors teaching English for Specific Purposes and 20 students' engineers. They were asked to respond to a textbook assessment tool envisaged by Joshua Miekly (2005). It is based on answering items related to checklist as a textbook assessment tools as envisaged by Joshua Miekly (2005). While students were interviewed so as to provide their opinions and attitudes vis-à-vis the content of the textbook they use. The purpose was to assess their learning choices and whether they think the course content was suitable for their needs and wants. Questions such as "do you think you benefitted from the course content? Did the content motivate your learning? From the variety of tasks offered, did you learn the sufficient technical knowledge you need for you future job career? Could you communicate your technical knowledge accurately and fluently?

Data collection: To assess the value of the textbooks, a version of an ESL textbook evaluation checklist was used and served as an instrument to evaluate the degree of communication enhancement. The scale was developed by Joshua Miekly (2005). To allow for administration across cultures, this checklist consisted of items in the form of questions, written in general terms, to be free of any specific cultural content and that can apply to any textbook. The teachers were asked to rate items on a 5-point Likert scale. Additional opinions and attitudes were collected via a semi-structured interview from teachers' engineers working at ENSAM. Analysis of data was carried out to cover content, skill-based, and linguistic and communicative features. The participants' responses in the interview were quantified percentally and analyzed using descriptive statistics.

\section{Results and discussion}

Critics such as Sandra (1988) found that textbooks, in almost every subject and grade level cover too many topics while the writing is sometimes superficial and changing, content, waver between essential and minor matters. Texts in these books failed to attract the imagination and needs of the students or make them reflect upon and reject current understanding about cognitive information, linguistic and communication processing (p. 212). Taking these aspects into account, one may ask why teachers rely so heavily on textbooks. The ultimate answer stems from the fact that the textbooks provide teachers with a clear outline they can use in planning courses, units, and lessons as well as ideas regarding the organization of information and activities, allowing them more time to prepare their lessons. 
In this paper, the textbooks recommended by the educational committee of My Ismail University students to teach English at the ENSAM School for engineering are:

- $\quad$ Soars, Liz \& J, Soars. (2008). New Headways Intermediate Student's Book. Oxford.

- $\quad$ Ibbotson, M. (2008). English for Engineering. Cambridge University Press

- Downes, C. (2008).Cambridge English for Job-hunting. Cambridge University Press.

New Headways, identified as an interesting textbook for students and teachers, blends two main approaches, namely traditional methodology, with a special focus on grammar and vocabulary, and a communicative approach, whereby skills are developed for spoken English. This textbook contains a functional syllabus, personalized practice, and authentic language work in real situations, as well as activities to encourage genuine communication inside and outside the classroom, covering the four skills, especially listening, speaking, reading, and writing. Each unit in the textbook has a wide range of practice activities, controlled and free, mechanical and information gap. Students are encouraged to analyze the target language and use it communicatively. The whole module of English covers 60 hours in one semester (S1, S3) with four teachers in charge of teaching content of the textbook in both years of the preparatory cycle.

The second textbook, Cambridge English for Engineering, improves the communication skills and professional English language awareness of future Engineers, allowing them to communicate more assertively and effectively with colleagues, customers, clients, and suppliers. The ten separate units cover topics common to all kinds of Engineering (including Civil, Electrical and Mechanical) such as procedures and precautions, monitoring and control, and Engineering design. Themes such as technology in use, engineering design, materials technology, and components and assemblies are taught and exploited. Authentic activities, from describing technical problems and suggesting solutions to working with drawings, make the course relevant and motivating. The stated aim of Cambridge English for Engineering is to improve professional communication skills. The course covers high-priority language that is useful in any branch of Engineering, focusing on skills such as working with drawings, describing technical problems and discussing dimensions and precision.

The third textbook, Cambridge English for Job-hunting, was reported to enhance the high-quality English language knowledge and communication skills that job-hunters need to apply for and secure jobs. Designed for not only working professionals but also for those new to the job market, the textbook comprises six units covering core areas such as CVs, sending 
letters, and responding to interview questions. Genuine resources, such as CVs and cover letters, offer learners useful experience in understanding and preparing active documents. The book also includes information to help raise job-seekers' confidence, including how to introduce oneself effectively.

Based on the descriptive analysis of the textbook, the following chart represents the distribution of tasks and skills.

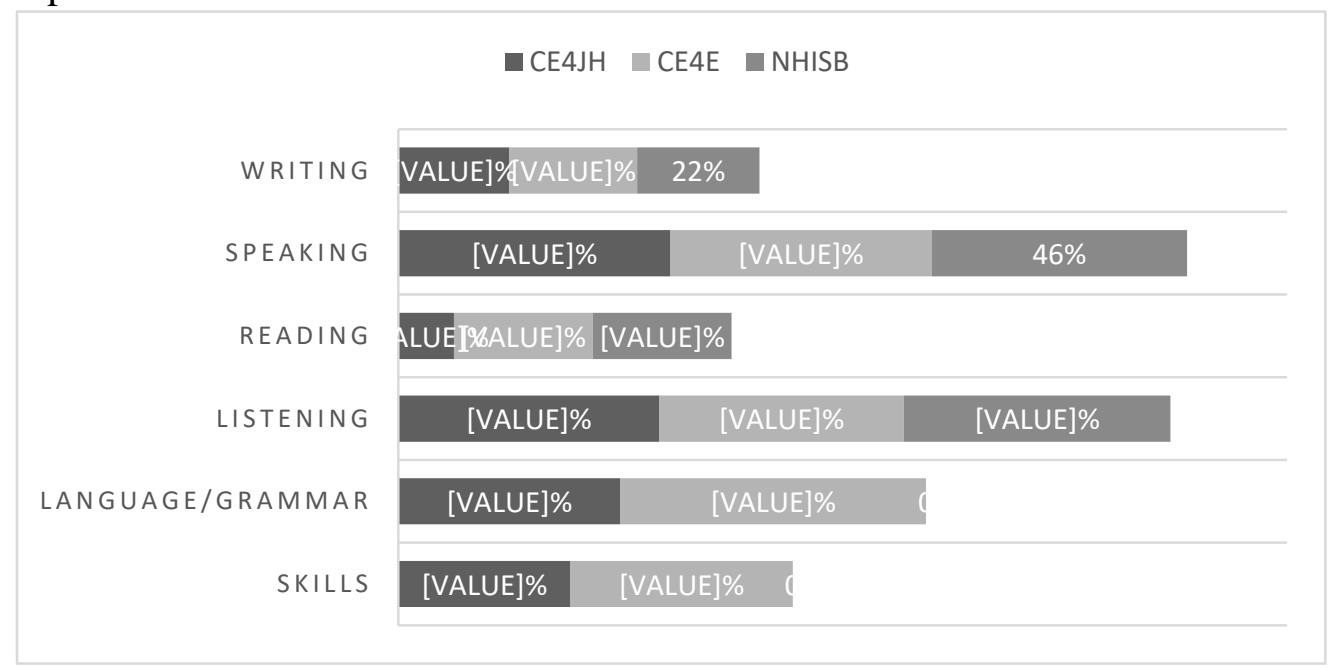

Table 1: Textbook Distribution of Tasks and Skills

Hence, it seems clear that the three textbooks put a premium focus on the four integrated skills, with an emphasis on listening (47\%-48\%), and speaking (46\%-49\%), whereas writing (20\%-22\%) and reading (10\%-25\%) complement the various competences presented to the students for learning. Since foreign language has become practically a compulsory skill for many jobs, it seems clear that employability skills are learned via the use English for fluency purposes. It is important to note that the ENSAM students are bilinguals with training and language instruction in both French and English. As result, they reinforce the content of their learning in the field of engineering.

The various opinions and attitudes of teachers insofar as the content, skills-based activities, and linguistic features of the textbook are represented in the subsequent tables. It is important to note that almost all teachers have already had an idea about the three textbook in the sense that they alternate in their teaching level every year. For this, questions about their attitudes visà-vis the overall textbooks were addressed in block. Besides, for the sake of clarification, NHISB is taught in the first and second year as a common core, $\mathrm{CE} 4 \mathrm{E}$ is used in the third year and fourth year, and CE4JH in the fifth year. 


\begin{tabular}{|c|c|c|c|c|c|}
\hline $\begin{array}{l}\text { New Headways intermediate Student's Book. } \\
\text { English for Engineering. } \\
\text { Cambridge English for Job-hunting. }\end{array}$ & 存苋 & 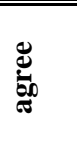 & 吾 & 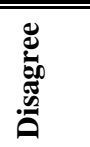 & 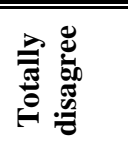 \\
\hline \multicolumn{6}{|l|}{ Content features } \\
\hline $\begin{array}{l}\text { The subject matter is presented topically in a } \\
\text { logical, organized manner? }\end{array}$ & $80 \%$ & $0 \%$ & $17 \%$ & $3 \%$ & $0 \%$ \\
\hline $\begin{array}{l}\text { Does the content help as a frame into learning } \\
\text { about the target language culture? }\end{array}$ & $0 \%$ & $75 \%$ & $0 \%$ & $25 \%$ & $0 \%$ \\
\hline $\begin{array}{l}\text { Are the reading selections authentic pieces of } \\
\text { language? }\end{array}$ & $35 \%$ & $45 \%$ & $0 \%$ & $20 \%$ & $0 \%$ \\
\hline $\begin{array}{l}\text { Compared to texts for native speakers, does the } \\
\text { content contain real-life issues that challenge the } \\
\text { reader to think unfavorably about his/her } \\
\text { worldview? }\end{array}$ & $0 \%$ & $80 \%$ & $0 \%$ & $20 \%$ & $0 \%$ \\
\hline
\end{tabular}

Table 2 Percentage Statistics of Items Related to Content Aspects Assessment

From these results on content features, almost all the participants show a positive attitude towards the organization of the subject matter (80\%), they feel that it helps in understanding the target culture (75\%), and offers a chance to revise one's worldview (80\%) through authentic material (35\%-45\%).These contents aspects recognizably help promote learning competences of communication. Hence, the findings of the study offer some support for the suitability of the textbooks to the Engineering needs identified for English as a language of instruction. A great proportion (35\% and $45 \%$ ) believes that the reading selections reveal the authentic language situations, able to enhance positive learning. This implies that teachers have the tendency to adjust their instructional practices to the overall performances of their students. The subsequent table illustrates teachers attitudes to the skill-based features incorporated in the textbooks.

Are the new vocabulary words presented in a variety of

Skill-based features

Are the grammar rules presented in a logical manner and in increasing order of difficulty? ways (e.g. glosses, multi-glosses, appositives)?

Are the new vocabulary words presented at an appropriate rate so that the text is understandable and so that students are able to retain new vocabulary?

Are students taught top-down techniques for learning new vocabulary words?

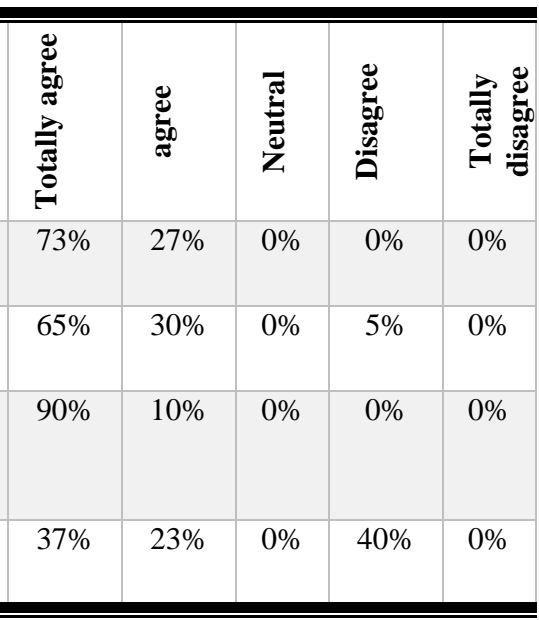

Table 3 Percentage Statistics of Items Related to Skill-based Aspects 
From the above results in table 3 , a close attention is paid to aspects of grammar, and glossary. Basically, such aspects are considered to be crucial in language mastery. Teachers have proven their positive attitude about how the various grammatical aspects are presented (73\% and 27\%). This means that students will benefit from various grammatical categories already learnt in high school but will be reinforced in their higher education. It is interesting to note that more than one half of the interviewees $(90 \%$, $37 \%$ ) agree that teaching vocabulary is presented at an appropriate rate and highly contextualized. However, only a small number or none $(40 \%, 0 \%)$ of the teachers responded negatively towards the teaching of vocabulary as an important aspect for the promotion of communicative competence.

As far as the linguistic and communicative aspects are concerned the table below shows that teachers highly agree with the numerous parts activities related to linguistic and communicative features. Indeed, 74\% totally agree that interactive and task-based activities help students to communicate, $81 \%$ believe that different activities facilitate communication, and $90 \%$ agree that the material taught is highly interactive and make communication easier among teacher and his students.

\begin{tabular}{|c|c|c|c|c|c|}
\hline $\begin{array}{l}\text { Linguistic and Communicative aspects: } \\
\text { Exercises and Activities }\end{array}$ & 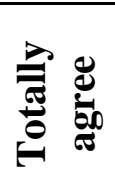 & 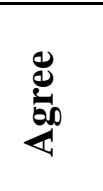 & 를 & 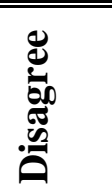 & 尝 \\
\hline $\begin{array}{l}\text { Are there interactive and task-based } \\
\text { activities that require students to use } \\
\text { new vocabulary to communicate? }\end{array}$ & $74 \%$ & $23 \%$ & $3 \%$ & $0 \%$ & $0 \%$ \\
\hline $\begin{array}{l}\text { Do instructions in the textbook tell } \\
\text { students to read for comprehension? }\end{array}$ & $12 \%$ & $12 \%$ & $11 \%$ & $65 \%$ & $0 \%$ \\
\hline $\begin{array}{l}\text { Do the activities facilitate students' use } \\
\text { of grammar rules by creating situations } \\
\text { in which these rules are needed? }\end{array}$ & $81 \%$ & $0 \%$ & $0 \%$ & $19 \%$ & $0 \%$ \\
\hline $\begin{array}{l}\text { Does the text make communication } \\
\text { easier by creating interaction between } \\
\text { the teacher/students among students? }\end{array}$ & $90 \%$ & $0 \%$ & $0 \%$ & $10 \%$ & $0 \%$ \\
\hline
\end{tabular}

Table 4Percentage Statistics of Items Related to Linguistic and Communicative Features

On the other hand, from the feedback of students interviewed on diverse aspects of teaching-learning process including motivation of the material in the textbooks, the findings reveal that a proportion of students $(12 / 20)$ admit that textbooks provide authentic materials that offer to them a chance to enlarge their technical knowledge because it highly motivating and meets the requirements of the engineering program. The findings also show that the textbooks impart the skills to the students and they feel that the exercises are sufficient for developing their basic skills. As the sample is 
limited, among the students in the engineering cycle six of out of eight chosen acknowledged that the final year syllabus content involves a lot of activities that helped them improve their language mastery at the level of speaking and writing. $1^{\text {st }}$ and $2^{\text {nd }}$ year students $(6 / 6)$ have responded negatively towards the way the material is taught because teachers, according to their views, should reduce the anxiety that students feel about certain topics.

Thus far, the analysis of the data obtained from the semi-structured interview confirms that various activities in the three textbooks bring about the improvement of learning conditions in various ways. Some of the benefits include acquiring academic and technical skills that promote their communicative competence. However, certain aspects still need to be enhanced so as to make the learning more enjoyable and interesting with the aim of ensuring students’ participation.

\section{Pedagogical implications}

This study has implications for multilingual communicative competence to improve multilingual competence by refining our theoretical explanations of the processes by which textbooks help in the realization of this purpose. Generally, the following findings of this study range from pedagogical organization to the attitudes of teachers and students.

First, the combination of task-oriented activities and skill-based patterns help the promotion of technical knowledge in English. Second, putting a premium interest on language and communicative skills, the choice of the three textbooks has proven effective in the sense that students continuously experience major changes in knowledge, equipment, tools, systems and managements as far as content is concerned. Third, students' mastery and understanding of the content activities related to their needs have relatively demonstrated an association between a strong theoretical background, and employability skills. It is important to note here that most teachers (80\%) agree that the content of the course meets the students' needs and therefore motivate their learning. Nevertheless, only a small proportion of teachers (3\%, 25\%, and 20\%)disagree that the textbook content should be reconsidered because the content is not well organized, and it does not help learning, and selections are not authentic “cf. table 2". Finally, the findings reveal that language teaching at the ENSAM School of engineering should be given more importance so as to develop other competences able to mediate between the internal traits of the students' background knowledge and language knowledge and the external characteristics of the situational and cultural context of the labor market. 


\section{Conclusion}

Thus far, the development of multilingual competence with relevant attributes, skills, and knowledge stands at the heart of Moroccan government interest. In fact, developing learning and teaching that promotes communication competences and enhances employability is the solution for the unemployment that might be encountered after having the diploma. The ENSAM School of Engineering has partly succeeded in enhancing the academic, personal and professional profile of students in order to meet the changing needs of employers, the economy and society. Nevertheless, other specialized methods of EFL learning have to be accommodated in order to respond to professional needs of the learners. Therefore, teacher training for language teachers in higher education schools, in general, needs to be developed and networking between such institutions should be encouraged and possibly financed through future programs. In order to improve the dialogue between education and the world of work, regional skills councils and similar forms of collaboration is encouraged with a view to enabling employers to take part in the continuous evaluation of teaching syllabuses and to contribute to guidance of students concerning their career choices.

\section{References:}

1. Bloomfield, L. (1993). Language. New York, NY: Holt, Rinehart and Winston.

2. Byram, M. S. (2012). Conceptualizing intercultural (communicative) competence and intercultural citizenship. In J. Jackson (Ed.), Routledge handbook of language and intercultural communication (pp. 85-97). Abingdon, United Kingdom: Routledge.

3. Canale, M. \&M. Swain, (1980). Theoretical bases of communicative approaches to second language teaching and testing. Applied Linguistics 29(1). 1-47

4. Cenoz, J., \& F. Genesee, (1998). Psycholinguistic perspectives on multilingualism and multilingual education.

5. Cenoz, J., \&F. Genesee, (Eds.). (1998). Beyond bilingualism: Multilingualism and multilingual education. Clevedon, UK. : Multilingual Matters.

6. Cenoz, J., \& D. Gorter, (2011). A holistic approach to multilingual education: Introduction. The Modern Language Journal, 95(3), 339343.

7. Coste D., D. Moore, \& G. Zarate, 1997, Compétence Plurilingue et Pluriculturelle, Conseil De L’Europe, Strasbourg.

8. Ennaji, M. (2005). Multilingualism, cultural identity, and education in Morocco. Springer

9. Science. Library of Congress Cataloging-in-Publication Data. 
10. Hymes, D. H. (1972). On communicative competence. In Pride, J.B.; Holmes, J. Sociolinguistics: selected readings. Harmondsworth: Penguin. pp. 269-293.

11. Joshua, M. (2005). ESL textbook evaluation checklist. The Reading Matrix. 5(2). $4 . \quad$ Retrieved from http://www.readingmatrix.com/reading_projects/miekley/project.pdf

12. Karimnia, A. \& I. Marziyeh (2007). On communicative and linguistic competence. International Journal of Communication. 27(2).

13. Kemp, C. (2009). Defining multilingualism. In L. Aronin \& B. Hufeisen (Eds.), the exploration of multilingualism (pp. 11-26). Amsterdam, the Netherlands: John Benjamins.

14. Marley, Dawn. (2004). Language attitudes in Morocco following recent changes in language policy. Language Policy, 3, 25-46.

15. Melouk, M. (2001).The State of EFL Evaluation in Morocco: The Testers and Teachers Opinions. Publications MATE, Morocco.

16. Sandra, C. (1988). Textbooks: Defining the New Criteria, Media and Methods. 64(2). 30-31.

17. Savignon, S. (1997). Communicative competence: theory and classroom practice: texts and contexts in second language learning (2nd Ed.). New York: McGraw-Hill. ISBN 978-0070837362.

18. Saville-Troike, M. (2006). Introducing second language acquisition. UK. : Cambridge University Press.

19. Skutnabb-Kangas, T. (2015). Linguicism. In C. A. Chapelle (Ed.), The encyclopedia of applied linguistics. Malden, MA: Blackwell.

20. Suresh Canagarajah, A. \& A. J. Wurr (2011). Multilingual Communication and Language Acquisition: New Research Directions. The Reading Matrix. 11(1), 1-15.

21. Tupas, R. (Ed.). (2015). Unequal Englishes: The politics of Englishes today. London, England: Palgrave Macmillan. 